\title{
Fungal mediated silver nanoparticle synthesis using robust experimental design and its application in cotton fabric
}

\author{
Sulbha Girish Velhal $^{1} \cdot$ S. D. Kulkarni ${ }^{2}$ R. V. Latpate $^{3}$
}

Received: 14 January 2016/ Accepted: 1 September 2016/Published online: 21 September 2016

(C) The Author(s) 2016. This article is published with open access at Springerlink.com

\begin{abstract}
Among the different methods employed for the synthesis of nanoparticles, the biological method is most favorable and quite well established. In microorganisms, use of fungi in the biosynthesis of silver nanoparticles has a greater advantage over other microbial mediators. In this study, intracellular synthesis of silver nanoparticles from Aspergillus terrerus (Thom) MTCC632 was carried out. We observed that synthesis of silver nanoparticles depended on factors such as temperature, amount of biomass and concentration of silver ions in the reaction mixture. Hence, optimization of biosynthesis using these parameters was carried out using statistical tool 'robust experimental design'. Size and morphology of synthesized nanoparticles were determined using X-ray diffraction technique, field emission scanning electron microscopy, energy dispersion spectroscopy, and transmission electron microscopy. Nanoembedded cotton fabric was further prepared and studied for its antibacterial properties.
\end{abstract}

Keywords Silver nanoparticles · Synthesis - Fibric . Antibacterial

Sulbha Girish Velhal

sulbhamadam@yahoo.co.in

S. D. Kulkarni

satishdkulkarni@gamil.com

R. V. Latpate

rvl@stats.unipune.ac.in

1 Department of Environmental Sciences, Savitribai Phule Pune University, Pune, India

2 New Arts, Commerce and Science College, Nagar, Pune, India

3 Department of Statistics, Savitribai Phule Pune University, Pune, India

\section{Introduction}

Silver is a naturally occurring precious metal, most often in the form of a mineral ore in association with other elements. Silver is well-known for its strong antibacterial activity which leads to the development of various nanosilver products. Recently, silver nanoparticles have been used in the medical field; wound dressing, surgical instruments, etc. [1-6]. In daily life, silver containing room sprays, laundry detergents, water purification systems, wall paints [7-11], clothes impregnated with silver nanoparticles [9], washing machines, etc. [10, 11] have been in use. Due to these extensive applications of silver nanoparticles, there is an increase in demand of their large scale synthesis with specific sizes and shapes. It is also well-known that the properties of silver nanoparticles are greatly influenced by its size, shape and crystal structure. Therefore, silver nanoparticles synthesis with defined size and shape are at the leading edge of nanoscience and nanotechnology.

Synthesis of silver nanoparticles is achieved by several physical, chemical and biological methods using top-down or bottom-up approaches [2, 12-18]. In the biosynthesis of silver nanoparticles, microorganisms have been extensively used to produce stable nanoparticles [19]. Hence, microorganisms have received the most attention in the area of silver nanoparticles synthesis due to their ability to absorb, accumulate, and synthesize silver nanoparticles [20]. Reports have proven that silver nanoparticles could be synthesized using microbes like bacteria [21, 22], fungi [23-27] and yeast as well as plant parts [28-31] and plant latex [32].

Among the microorganisms, fungal mediated silver nanoparticles synthesis is a relatively new research area [32, 33]. Many fungal species have been studied for their ability to synthesize silver nanoparticles. Some 
representative examples are shown in Table 1. Compared to bacteria, fungi have an advantage in large-scale production as it produces large amounts of enzymes involved in silver nanoparticle synthesis. Moreover, fungal culture is simpler to grow both in the laboratory and at industrial scale.

Studies (Table 1) suggested that there are two major routes of fungal mediated silver nanoparticle synthesis: (a) using cell-free broth or extract and (b) using dried or wet mycelia. In the biosynthesis of silver nanoparticles using Verticillium spp., homogeneous distribution of nanoparticles in cell wall has been reported [26]. In the fungus Aspergillus flavus [33], accumulation of silver nanoparticle on the surface of its cell wall was observed when placed in silver nitrate solution are some examples of fungal mediated intracellular synthesis of silver nanoparticles. Hence, the present paper describes the preparation and optimization of silver nanoparticle synthesis to obtain specific size and shape of silver nanoparticles.

\section{Materials and methods}

\section{Cultivation of microorganisms}

In this study, the fungus Aspergillus terrerus (Thom) MTCC 6624 was used for the synthesis of silver nanoparticles. The fungal culture was obtained from Microbial Type Cultural Collection and Gene Bank, Institute of Microbial Technology, Chandigarh, India. Pure culture was maintained on the medium $(\mathrm{g} / \mathrm{l}$ : malt extract, 3.0; glucose 10.0; yeast extract 3.0; peptone 5.0 and agar 25.0) as prescribed by MTCC, Chandigarh, India and subcultured at monthly intervals.

\section{Production of fungal biomass}

For pre-inoculum development, $A$. terrerus from the $1 / 5$ th slant was inoculated in Erlenmeyer flask $(250 \mathrm{ml})$ containing glucose $1.5 \mathrm{~g}$ (Hi-Media), peptone (Hi-Media) $1.0 \mathrm{~g}$ and yeast extract (Hi-Media) $0.35 \mathrm{~g}$ per $100 \mathrm{ml}$. In the inoculated medium, potassium nitrate $(0.35 \mathrm{~g} / \mathrm{l})$ was

Table 1 Silver nanoparticles synthesis by fungi

\begin{tabular}{llll}
\hline S. no. & Name of organism & $\begin{array}{l}\text { Particle } \\
\text { size nm }\end{array}$ & References \\
\hline 1. & Verticillum spp. & 25 & {$[25]$} \\
2. & Fusarium oxysporum & $20-50$ & {$[31]$} \\
3. & Phanerochaete chrysosporium & 100 & {$[32]$} \\
4. & Aspergillus fumigatus & $5-25$ & {$[33]$} \\
5. & Aspergillus flavus & $7-10$ & {$[34]$} \\
6. & Coriolus versicolor & $350-600$ & {$[35]$} \\
7. & Fusarium solani & $5-35$ & {$[36]$} \\
\hline
\end{tabular}

added so as to stimulate the culture to produce nitrate reductase enzyme complex. Cells were grown aerobically at $30{ }^{\circ} \mathrm{C}$ under shaking at $120 \mathrm{rpm}$ for $72 \mathrm{~h}$. The culture containing medium was centrifuged at $9000 \mathrm{rpm}$ for $10 \mathrm{~min}$ at $4{ }^{\circ} \mathrm{C}$. The cell biomass was washed thrice with one volume of sterile distilled water. The biomass was vacuum dried at $50{ }^{\circ} \mathrm{C}$ and used for silver nanoparticle synthesis.

\section{Synthesis of silver nanoparticles}

For each run, $50 \mathrm{ml}$ of silver nitrate solution was prepared in $250 \mathrm{ml}$ Erlenmeyer flask. As per the statistical experimental design, a specific amount of fungal biomass was inoculated into the silver nitrate solution and incubated at a specific temperature for $24 \mathrm{~h}$ (Table 2). The control flask containing silver nitrate solution without biomass was also incubated at desired temperature for $24 \mathrm{~h}$. After incubation, the solution was filtered by membrane filtration technique using $2.0 \mu \mathrm{m}$ filter paper. The obtained biomass was washed thrice with deionized distilled water and then vacuum dried at $50{ }^{\circ} \mathrm{C}$. These experiments were performed in duplicate and mean value were used further for result analysis. The results obtained after conducting the experiments were analyzed by MiniTab software to make it a reference about the factors involved in the synthesis of silver nanoparticles. Finally, the optimum operating conditions for synthesis of smaller size nanoparticles were determined.

\section{Characterization of silver nanoparticles}

\section{Ultra violet-visible (UV-Vis) spectrophotometry}

The UV-Vis spectrum of the dried powder was recorded with JASCO V670 spectrophotometer at wavelengths ranging from 200 to $800 \mathrm{~nm}$.

\section{Field emission scanning electron microscopy (FE-SEM)}

An FE-SEM is used to visualize very small topographic details on the surface of the particles. This technique is used to observe the structural details of synthesized nanoparticles, polymers, and organelles at a smaller

Table 2 Factors and their values used during experiments

\begin{tabular}{lllll}
\hline & Factor & \multicolumn{2}{l}{ Levels } & \\
\cline { 3 - 5 } & & 1st & 2nd & 3rd \\
\hline $\mathrm{C}$ & Temperature $\left({ }^{\circ} \mathrm{C}\right)$ & 35 & 40 & 45 \\
$\mathrm{~B}$ & Biomass $(\mathrm{g})$ & 0.3 & 0.5 & 0.7 \\
$\mathrm{~A}$ & $\mathrm{AgNO}_{3}(\mathrm{mM})$ & 6.0 & 8.0 & 10.0 \\
\hline
\end{tabular}


$(>1 \mathrm{~nm})$ scale. Electrons liberated are from a field emission source that generates a high electron field gradient in the high vacuum column. From this column, a narrow scanning beam is bombarded on the material. As a result, secondary electrons are emitted from the material which gathers on the detector to produce an electronic signal. This amplified signal can scan on a monitor as a digital image. Hence, FESEM is useful in qualitative and quantitative analysis of elemental composition and distribution in the sample. To obtain FE-SEM image of the synthesized material, the instrument Nova Nano SEM 450, make FEI, and software $\mathrm{xT}$ microscope control was used.

\section{$X$-ray diffraction $(X R D)$}

X-ray powder diffraction is a rapid, versatile and a nondestructive analytical technique used for quantitative and qualitative analysis of crystalline materials. This technique is used to determine the overall structure of a single crystal, its structure, texture, particle size, and average bulk composition of the material. In this study, a powder diffraction system with $\mathrm{Cu}-\mathrm{K} \alpha(\lambda=0.1542 \mathrm{~nm})$ was used. The X-ray scans were performed between $2 \theta$ values $20^{\circ}-90^{\circ}$ with a step size of about 0.10 using Burker 9XS, D8 advance model, Germany.

In a crystal, atoms are arranged in a lattice. When Xrays are scattered from the crystalline solid they produce a diffracted beam through the crystal. In 1912, W. L. Bragg recognized a predictable relationship between several factors and combined them in an equation in Bragg's law:

$n \lambda=2 d \sin \theta$

Here, $\lambda$, the wavelength of the rays; $\theta$, the angle between the incident rays and the surface of the crystal; $d$, the spacing between layers of atoms; and $n$, an integer.

Crystalline size measurement: Scherrer's formula X-ray diffraction is used for identification of phase on the basis of the position of the peaks in diffraction profile as well as the relative intensities of these peaks to some extent. The diffraction of the peak depends on the presence of various types of defects in a crystal. Small size crystal is one of the defects which can change the width of diffraction peak. Therefore, crystal size is easily calculated by Scherrer's formula as peak with (specified as the full-width at half maximum peak intensity), peak position, and wavelength. The Scherrer's formula is;

Crystallite size $L=\frac{K \times \lambda}{\beta \times \cos \theta}$

Here $L$, the Scherrer's constant of value $0.94 ; \lambda$, the X-ray wavelength $(0.1542 \mathrm{~nm}) ; \beta$, the half-height width of the diffraction band; and $\theta$, the Bragg angle corresponding to planes. Thus, the size obtained from this formula is the apparent or average particle for material under study.

\section{Preparation of silver nano-embedded cotton fabric}

The cotton fiber was used for the preparation of silver nanoparticles loaded material. Long thread Egyptian cotton fibers were purchased from local market. The fibers were washed, combined into about $10 \mathrm{~cm}$ width strips, dried and then cut into $10 \mathrm{~cm}$ long segments. Silver nanoparticles were separated from the fungal biomass by mild acid treatment $(0.1 \mathrm{~N} \mathrm{HCl}$ for $2 \mathrm{~h})$. After acid treatment, concentration of obtained silver nanoparticles was 1000 ppm. This initial concentration of nanoparticles was further diluted to obtain 25 and 100 ppm with distilled water. The cotton fabric was immersed in this silver colloidal bath for $10 \mathrm{~min}$ and excess liquid was squeezed out. This material was then dried at $50{ }^{\circ} \mathrm{C}$ for $30 \mathrm{~min}$ and pellets of $5 \mathrm{~mm}$ diameter were prepared for further study.

\section{Antibacterial properties of silver nanoparticles embedded fabric}

Bacterial strains used during the studies are listed in Table 3. Cultures were grown at $30{ }^{\circ} \mathrm{C}$ for 24 on MuellerHinton medium (MH agar per liter: beef infusion 300, casein hydrolysate $17.50 \mathrm{~g}$, starch $1.50 \mathrm{~g}$ and agar $17.0 \mathrm{~g}$ ) plates. The newly grown single colony was inoculated with 3.0-5.0 $\mathrm{ml}$ of $\mathrm{MH}$ broth and incubated at $37^{\circ} \mathrm{C}$ till turbidity of the medium attained to 0.5 .

\section{Results and discussion}

\section{Synthesis of silver nanoparticles}

Many physical and chemical methods had been reported for synthesis of silver nanoparticles [34-38]. One of the main reasons for the development of the present method of synthesis is at the nano- and sub-nano levels, the particles are much more unstable and impart special properties to the material [38]. Although the use of physical and chemical methods yield smaller size nanoparticles but the use of

Table 3 Microorganisms used in the study

\begin{tabular}{llr}
\hline S. no. & Strain name & $\begin{array}{l}\text { ATCC } \\
\text { No. }\end{array}$ \\
\hline 1. & Escherichia coli & 25922 \\
2. & Bacillus cereus & 11778 \\
3. & Pseudomonas aeruginosa & 27853 \\
4. & Staphylococcus aureus & 9144 \\
5. & Proteus vulgaris & 13315 \\
\hline
\end{tabular}


capping agents or nanocavities are few examples of their limitations. Therefore, attention is being directed to produce silver nanoparticles using environmental friendly methods [19]. The use of microbial cells for the synthesis of nano-sized materials has emerged as a novel approach for the synthesis of metal nanoparticles. The microbial system like bacteria, fungi and yeast has the ability to convert metal ions to metallic nanoparticles [22, 23, 25, 26]. Among these, fungal species are widely used as tools for this purpose and has more advantages in the production of nanoparticles [25, 26].

In this study, silver nanoparticles were synthesized using a fungal system. During synthesis, change in the color of biomass from pale white to brown was the indication of conversion of $\mathrm{Ag}^{++}$to $\mathrm{Ag}^{0}$, while the control showed no color change. This color change could be due to the shift in the surface plasmon resonance where silver as $\mathrm{Ag}^{++}$is reduced to silver nanoparticles (Eq. 3) [39].

$\mathrm{Ag}^{++}+\mathrm{e}^{2-}>\mathrm{Ag}_{(\mathrm{s})}$

When the wavelength of specific light interacts with silver nanoparticles, the electrons on the surface are excited and undergo oscillations. However, various metals have variable excitation and oscillation spectra. The known excitation spectra for silver nanoparticles were used for specific identification of the nanoparticles using UV-Vis spectrophotometer. As shown in Fig. 4, the particles were scanned at 200-800 nm and absorbance peak was obtained at $290 \mathrm{~nm}$.

That classic UV-Vis peak of silver nanoparticles shifted from 390 to $290 \mathrm{~nm}$ may be due to various mechanisms involved during their synthesis. These mechanisms have been suggested in many reports. For example, binding of silver ions with fungal cell wall during [19, 22] synthesis. Entrapment of silver nanoparticles on the cell wall of microbes is suggested in studies. The presence of the carboxyl group of amino acid residues and the amine of peptide chains along with reducing groups like aldehyde and ketone governs the bioreduction of silver ions to $\left[\mathrm{Ag}\left(\mathrm{NH}_{3}\right)_{2}\right]^{+}$ group [40]. It has been also reported that the presence of dehydrogenase and nitrate reductase plays an important role in synthesis of silver nanoparticles [41-43]. Hence, fungal cell wall mediated silver nanoparticle synthesis could be possible while the presence of carboxyl group of amino acid enhances the entrapment of nanoparticles intracellularly.

\section{Optimization of biosynthesis parameters}

The effect of silver ions on silver nanoparticle synthesis was studied by varying the concentration of silver nitrate (Table 2). The finely milled fungal biomass was treated with $6.0,8.0$, and $10.0 \mathrm{mM}$ solution of silver nitrate. Primary experiments showed that the size of nanoparticles decreased as the concentration of silver ions decreases. It could be possible that the low concentration of silver ions stimulates various functional groups on the fungal cell wall. These functional groups convert $\mathrm{Ag}^{++}$to $\mathrm{Ag}^{0}$ and cause the formation of silver nanoparticles of smaller diameter (Eq. 2). As more silver ions become available, the size of the particles increases (Fig. 1); the threshold concentration of silver ions responsible for lowest particle diameter was found to be $6 \mathrm{mM}$.

Figure 2 indicates the effect of fungal biomass on the synthesis of silver nanoparticles and the optimum value was found to be $0.7 \mathrm{~g} / 100 \mathrm{ml}$. It was observed that lower the amount of biomass concentration, comparatively larger was the particle size.

Effect of temperature on the size of particle was studied at three levels $\left(35^{\circ} \mathrm{C}, 40{ }^{\circ} \mathrm{C}\right.$, and $45^{\circ} \mathrm{C}$ ) (Fig. 3). However, smaller particle was obtained at temperature of $45^{\circ} \mathrm{C}$, it could be due to the change in permeability of cell at high temperature which support smaller size silver nanoparticle synthesis.

\section{Analysis of variance (ANOVA)}

Analysis of variance (ANOVA) consists of classifying and cross-classifying results and testing whether the means of a specified classification differ significantly or not [44]. For this, the statistical significance of each parameter was studied by $p$ value and it was assumed that smaller the magnitude of $p$ value, more significance was studied, shown in Table 4.

The results presented in Table 5 demonstrate that synthesis of silver nanoparticles was significantly affected by the concentration of silver ions and reaction temperature of the synthesis process. Therefore, we report here that silver nanoparticles of size $\sim 2.0 \mathrm{~nm}$ are possible to produce

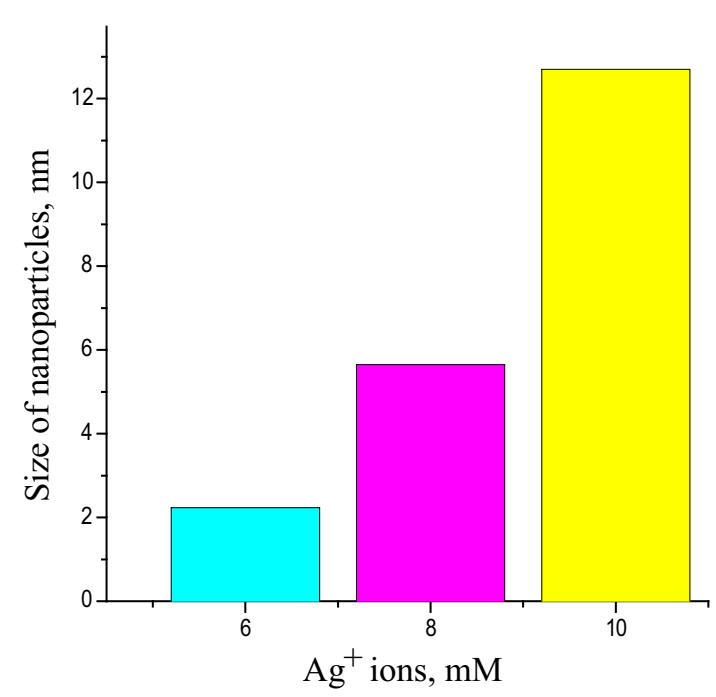

Fig. 1 Effect of silver ion concentration on the size of nanoparticles 


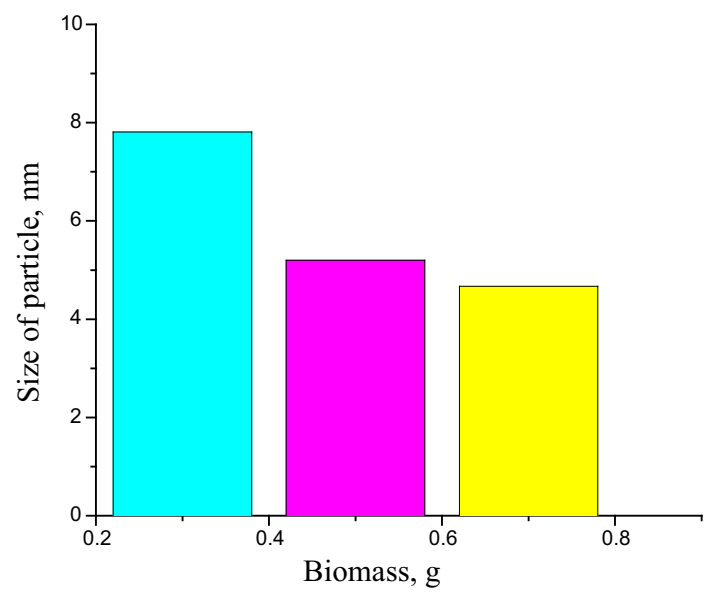

Fig. 2 Effect of fungal biomass on the size of nanoparticles

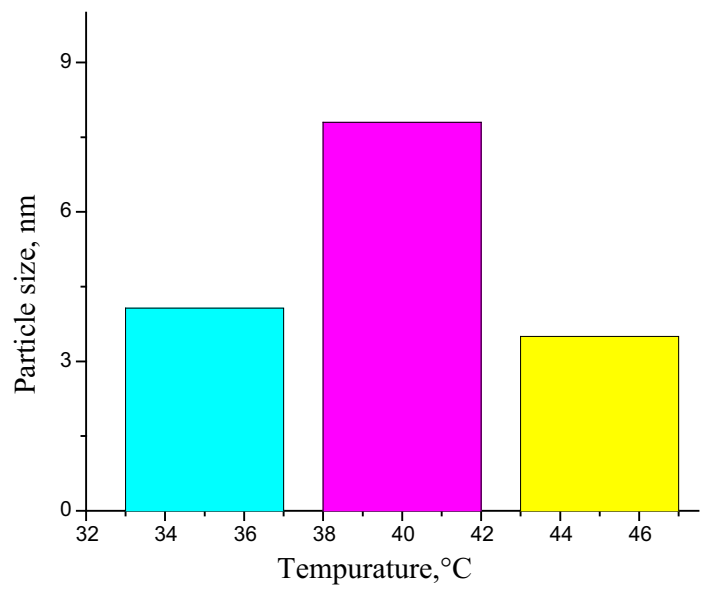

Fig. 3 Effect of temperature on the size of nanoparticles

Table 4 Analysis of variance for $\mathrm{S} / \mathrm{N}$ ratio

\begin{tabular}{llrlrll}
\hline Source & $D F$ & Seq SS & Adj SS & Adj MS & $F$ & $P$ \\
\hline A & 2 & 31.79 & 31.79 & 15.895 & 2.00 & 0.334 \\
B & 2 & 22.47 & 22.47 & 11.234 & 1.41 & 0.415 \\
C & 2 & 31.78 & 31.78 & 15.890 & 2.00 & 0.334 \\
Residual error & 2 & 15.92 & 15.92 & 7.959 & & \\
Total & 8 & 101.96 & & & & \\
$R^{2}=81.7 \%$ & & & & & & \\
\hline
\end{tabular}

when silver nitrate is at low level $(6.0 \mathrm{mM})$ and temperature at high level $\left(45^{\circ} \mathrm{C}\right)$.

\section{Characterization of silver nanoparticles}

\section{Ultra violet-visible spectrophotometery}

Metallic nanoparticles have a specific optical adsorption spectrum in the UV-visible region. The surface of a metal is like plasma, having free electrons in the conduction band
Table $5 \quad \mathrm{~L}_{9}\left(3^{3}\right)$ orthogonal array

\begin{tabular}{|c|c|c|c|c|c|c|}
\hline \multirow[t]{2}{*}{ S. no. } & \multicolumn{3}{|c|}{ Factors } & \multicolumn{2}{|c|}{$\begin{array}{l}\text { Size of silver } \\
\text { nanoparticles }(\mathrm{nm})\end{array}$} & \multirow[t]{2}{*}{$\begin{array}{l}\text { Nanoparticles size } \\
\text { (mean values) }\end{array}$} \\
\hline & A & B & $\mathrm{C}$ & Run1 & Run2 & \\
\hline 1. & 1 & 1 & 1 & 4.30 & 8.20 & 6.40 \\
\hline 2. & 1 & 2 & 2 & 4.60 & 3.30 & 3.95 \\
\hline 3. & 1 & 3 & 3 & 0.36 & 4.10 & 2.0 \\
\hline 4. & 2 & 1 & 2 & 5.10 & 11.6 & 12.7 \\
\hline 5. & 2 & 2 & 3 & 5.50 & 6.20 & 5.65 \\
\hline 6. & 2 & 3 & 1 & 5.70 & 4.80 & 5.15 \\
\hline 7. & 3 & 1 & 3 & 4.10 & 4.60 & 4.35 \\
\hline 8. & 3 & 2 & 1 & 6.70 & 5.50 & 6.10 \\
\hline 9. & 3 & 3 & 2 & 7.40 & 5.90 & 6.65 \\
\hline
\end{tabular}

Bold values indicate optimum operating conditions for silver nanoparticle synthesis

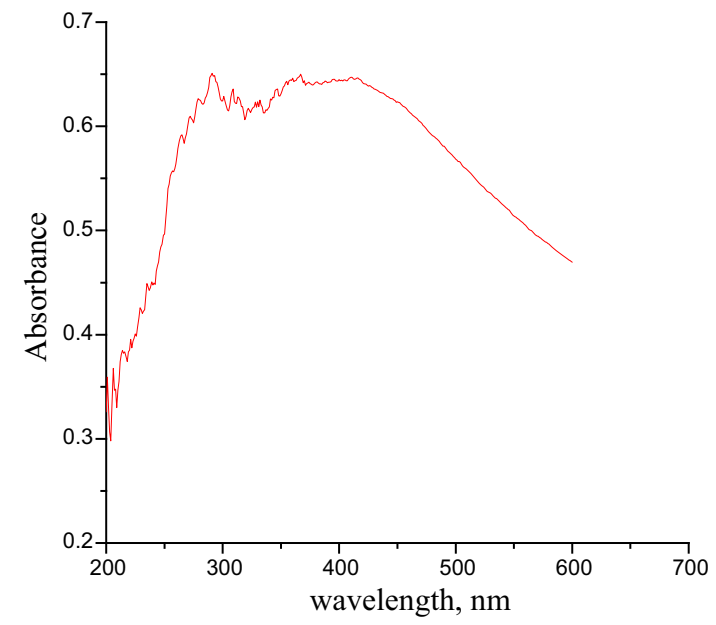

Fig. 4 UV-visible spectrum of synthesized particles

and positively charge nuclei. Therefore, surface plasmon resonance is due to shift of the absorption spectrum of silver nanoparticles into the UV-visible region. As shown in Fig. 4, UV-visible spectra of silver nanoparticles have a broad and strong peak at $290 \mathrm{~nm}$. This specific absorption peak of silver nanoparticles is due to excitation of electrons in the construction band [45]. The electrons of silver nanoparticles are excited in presence of UV light toward the surface and form a characteristic peak of silver nanoparticles [38, 46, 47] at $290 \mathrm{~nm}$ (Fig. 5).

\section{Field emission scanning electron microscopy results}

In fungal mediated biosynthesis, when the aqueous silver nitrate solution was exposed to fungal biomass, silver was adsorbed on the surface of the mycelia and further reduced the metal ions to atoms [46]. These metal atoms further coalesce to form aggregates. As shown in Fig. 6, silver 


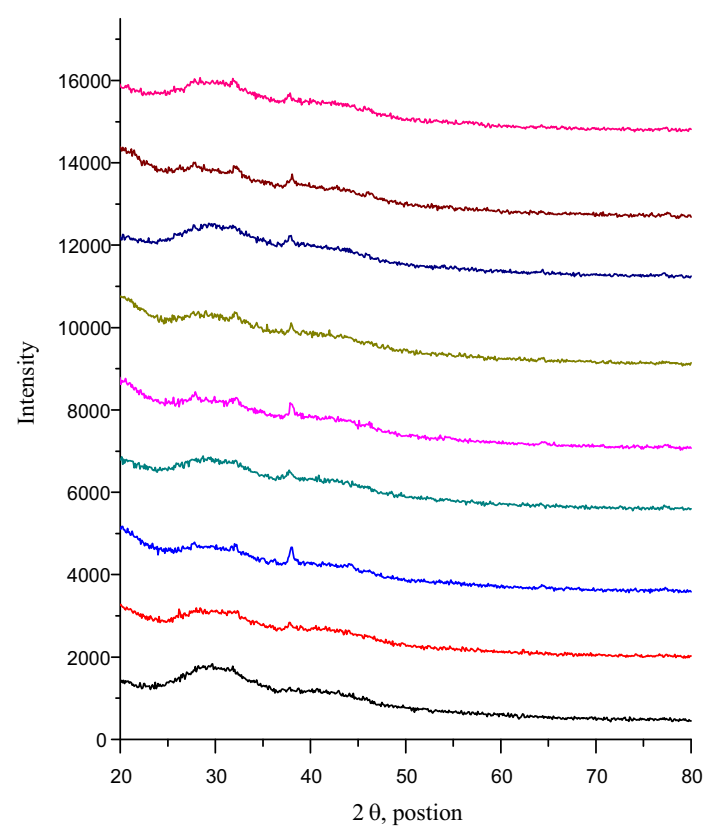

Fig. 5 X-ray diffraction of synthesized nanoparticles

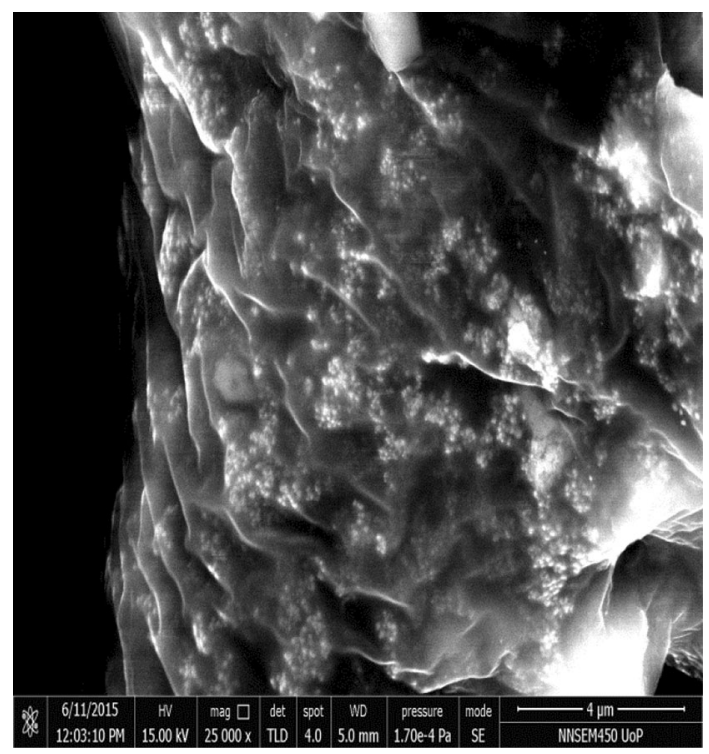

Fig. 6 SEM image of nanoparticle

nanoparticles were reduced intracellularly on the surface of the mycelium. This fungal mediated reduction resulted in formation of silver nanoparticles and was stabilized by various functional groups present in fungal cell wall. There could be two possible mechanisms for intracellular synthesis of silver nanoparticles; (a) functional groups such as $-\mathrm{C}-\mathrm{O}-\mathrm{C}-,-\mathrm{C}-\mathrm{O}-$, and $-\mathrm{C}=\mathrm{C}=$ derived from heterocyclic compounds and the amide I bond derived from proteins is responsible for capping ligands of the nanoparticles $[38,43,48,49]$ and (b) presence of nitrate reductase in the fungal cell is responsible for reducing the silver ions to
Table 6 Antibacterial study of silver nano-embedded cotton fabric

\begin{tabular}{llll}
\hline S. no. & Microbes used & \multicolumn{2}{l}{$\begin{array}{l}\text { Concentration of } \\
\text { silver nanoparticles }\end{array}$} \\
\cline { 3 - 4 } & & $25 \mathrm{ppm}$ & $100 \mathrm{ppm}$ \\
\hline 1. & Escherichia coli & + & - \\
2. & Bacillus cereus & - & - \\
3. & Pseudomonas aeruginosa & + & - \\
4. & Staphylococcus aureus & - & - \\
5. & Proteus vulgaris & + & - \\
\hline
\end{tabular}

'-', indicates inhibition of growth and ' + ' presence of growth of microbes

nanoparticles. In the present investigation, morphology of the synthesized nanoparticles was studied by FE-SEM and they were found to be spherical in shape.

\section{$X$-ray diffraction results}

The X-ray diffraction tool is known to calculate the approximate particle size of nanoparticles. The average particle size was calculated by Scherrer's equation (Eq. 2) and found to be $\sim 2.0 \mathrm{~nm}$. The blue shift of surface plasmon resonance denotes decrease in particle diameter.

\section{Antibacterial property of silver nano-embedded cotton fabric}

Recently, the use of cellulose carriers for microbial treatment is a new area of textile research. Various nanoparticles were studied for their application in the textile industry $[2,50,51]$. The silver metal is very well known for its antibacterial properties and could be a good agent for bacterial resistant fabric. It has inhibitory effect on many microbes and could be helpful to control multi-drug resistant microorganisms. This possibility was studied using a prototype of cotton fabric embedded with silver nanoparticles. Therefore, it is proposed that a novel hybrid of cotton fiber to silver nanoparticles may have antibacterial property.

The cotton fibers loaded with 25 and 100 ppm concentration of silver nanoparticles was used during this study. It was observed that lowest concentration of silver nanoparticles exhibited good antibacterial properties.

The Gram positive Bacillus cereus and Staphylococcus aureus are more susceptible to silver nanoparticles than Gram negative Pseudomonas aeruginosa, Escherichia coli, and Proteus vulgaris. Whereas increase in concentration to $100 \mathrm{ppm}$, inhibit the growth of both Gram positive and Gram negative of microbes, while non silver embedded cotton fabric did not show antibacterial property. Hence, silver nanoparticles impart an antibacterial property to the cotton fabric as it provides a large surface area for their adhesion (Table 6). 


\section{Conclusion}

Our X-ray diffraction study showed that silver nanoparticles of size ranging from maximum $\sim 13.80$ to $2.0 \mathrm{~nm}$ were produced during synthesis. The UV-Vis spectra indicated that the surface plasmon resonance of silver nanoparticles shifted to $290 \mathrm{~nm}$ due to cell-bound nature of nanoparticles. The obtained FE-SEM images showed that the silver nanoparticles are present intracellularly. It is proposed that silver nanoparticles synthesized by biological route is smaller than those synthesized chemically. Antibacterial property was also demonstrated by fabric embedded with silver nanoparticles. Thus, it can be concluded that the silver nano-embedded fabric has excellent antibacterial properties and could be applied at large scale.

Open Access This article is distributed under the terms of the Creative Commons Attribution 4.0 International License (http://crea tivecommons.org/licenses/by/4.0/), which permits unrestricted use, distribution, and reproduction in any medium, provided you give appropriate credit to the original author(s) and the source, provide a link to the Creative Commons license, and indicate if changes were made.

\section{References}

1. Muangman, P., Chuntrasakul, C., Silthram, S., Suvanchote, S., Benjathanung, R., Kittidacha, S., Ruekosomtawin, S.: Comparison of efficacy of $1 \%$ silver sulfadiazine and anticoat for treatment of partial-thickness burn wounds. J. Med. Assoc. Thail. 89, 953-958 (2006)

2. Lansdown, A.B.: Silver in health care: antibacterial effects and safety in use. Curr. Probl. Dermatol. 33, 17-34 (2006)

3. Raad, I.I., Hanna, H.A.: Intracellular catheter-related infections. New horizons and recent advances. Arch. Intern. Med. 162, 871-878 (2002)

4. Hotta, M.H., Nakajima, K., Yamamoto, K., Aono, M.: Antibacterial temporary filling materials: the effect of adding various ratios of Ag-Zn-zeolite. J. Oral Rehabil. 25, 485-489 (1998)

5. Mastsuura, T., Abe, Y., Sato, Y., Okamoto, K., Ueshiqe, M., Akaqawa, Y.: Prolonged antibacterial effect of tissue conditions containing silver-zeolite. J. Dent. 25, 373-377 (1997)

6. Dowsett, C.: The use of silver-based dressing in wound care. Nurs. Stand. 19, 56-60 (2004)

7. Liu, Z., Stout, J.E., Tedessco, L., Boldin, M., Hwang, C., Diven, W.F., Yu, V.L.: Controlled evolution of copper-silver ionization in eradicating Legionella pneumophila from a hospital water distribution system. J. Infect. Dis. 169, 919-922 (1994)

8. Takai, K., Ohtsuka, T., Senda, Y., Nakao, M., Yamamoto, K., Matsuoka, J., Hirai, Y.: Antibacterial properties of microbialfinished textile products. Microbiol. Immunol. 46, 75-81 (2002)

9. Lee, H.Y., Park, H.K., Lee, Y.M., Kim, K., Park, S.B.: A practical procedure for producing silver nanocoated fabric and its antibacterial evolution for biomedical applications. Chem. Commun. 28, 2959-2961 (2007)

10. http://www.samsung.co.za/silvernano/silvernano/wash.html

11. Chaki, N.K., Vijayamohanan, K.: Self-assembled monolayers as a tenable platform for biosensor applications. Biosens. Bioelectron. 17, 1-12 (2002)
12. Joerger, R., Klaus, T., Granqvist, C.G.: Biologically produced silver-carbon composite materials for optically functional thinfilm coatings. Adv. Mater. 12, 407-409 (2000)

13. Sun, Y., Xia, Y.: Shape-controlled synthesis of gold and silver nanoparticles. Science 298, 2176-2179 (2002)

14. Mafune, F., Kohno, Y., Takeda, Y., Kondow, T., Sawabe, H.: Formation and size control of silver nanoparticles by laser ablation in aqueous solution. Phys. Chem. B 105, 9111-9117 (2001)

15. Raffi, M., Rumaiz, A.K., Hasan, M.M., Shah, S.I.: Studies of the growth parameters for silver nanoparticles synthesis by inert gas condensation. J. Mater. Res. 22, 3378-3384 (2007)

16. Rosemary, M.J., Pradeep, T.: Solvothermal synthesis of silver nanoparticles from thiolates. J. Colloid Interface Sci. 268, 81-84 (2003)

17. Kalathill, S., Lee, J., Cho, M.H.: Electrochemically active biofilm-mediated synthesis of silver nanoparticles by Bacillus licheniformis. Colloids Surf. B Biointerfaces. 65, 150-151 (2008)

18. Fu, M., Qingbiao, Li., D., Sun, Y., Lu, N., He, N., Deng, X., Wang, H., Huang, J.: Rapid preparation process of silver nanoparticles by bioreduction and their characterizations. Chin. J. Chem. Eng. 14, 114-117 (2006)

19. Mukherjee, P., Ahmad, A., Mendal, D., Senapati, S., Sainkar, S.R., Khan, M.I., Parischa, R., Ajayakumar, P.V., Alam, M., Kumar, R., Sastry, M.: Fungus-mediated synthesis of silver nanoparticles and their immobilization in the mycelia matrix: a novel biological approach to nanoparticles synthesis. Nano Lett. 1, 515-519 (2001)

20. Lenqke, M.F., Fleet, M.E., Southam, G.: Biosynthesis of silver nanoparticles by flimentous cyanobacteria from a silver (1) nitrate complex. Langmuir 27, 2694-2699 (2007)

21. Pham, H.N., McDowell, T., Wilkins, E., Hazard, T.: Photocatalytically-mediated disinfection of water using $\mathrm{TiO}_{2}$ as a catalyst and spore-forming Bacillus pumilus as a model. Sci. Eng. Health A30, 627-636 (1995)

22. Fu, J.K., Zhang, W.D., Liu, Y.Y., Yao, B.X., Weng, S.Z., Zeng, J.L.: Characterization of adsorption and reduction of noble metal ions by bacteria. Chem. J. Chin. Univ. 20(9), 1452-1454 (1999)

23. Fu, J.K., Liu, Y.Y., Gu, P.Y., Tang, D.L., Lin, Z.Y., Yao, B.X., Weng, S.Z.: Spectroscopic characterization on the biosorption and bioreduction of ag(l) by Lactobacillus sp. A09. Acta. Phys Chim. Sin. 16, 779-782 (2000)

24. Khabat, V., Mansoori, G.A., Karimi, S.: Biosynthesis of silver nanoparticles by fungus Trichoderma reesei. Insci. J. 1, 65-79 (2011)

25. Vigneshwaran, N., Kathe, A.A., Varadarajan, P.V., Nachane, R.P., Balasubramanya, R.H.: Biomimetics of silver nanoparticles by white rot fungus Phaenerochaete chrysosporium. Collids Surf. B Biointerfaces 53, 55-59 (2006)

26. Bhainsa, K.C., D'Souza, S.F.: Extracellular biosynthesis of silver nanoparticles using the fungus Aspergillus fumigates. Colloids Surf. B Biointerfaces 47, 160-164 (2006)

27. Mandal, D., Bolander, M.E., Mukhopadhyay, D., Sarkar, G., Mukherjee, P.: The use of microorganisms for the formation of metal nanoparticles and their application. Appl. Microbiol. Biotechnol. 69, 485-492 (2006)

28. Shankar, S.S., Rai, A., Ahmad, A., Sastry, M.: Rapid synthesis of $\mathrm{Au}, \mathrm{Ag}$, and bimetallic $\mathrm{Au}$ core-Ag shell nanoparticles using Neem (Azadirachta indica) leaf broth. J. Colloid Interface Sci. 275, 496-502 (2004)

29. Philip, D.: Green synthesis of gold and silver nanoparticles using Hibiscus rosa-sinensis. Physica E Low Dimens. Syst. Nanostruct. 42, 1417-1424 (2010)

30. Bar, H., Bhui, D.K., Sahoo, G.P., Sarkar, P., De, P.S., Misra, A.: Green synthesis of silver nanoparticles using latex of Jatropha curcas. Colloids Surf. A: Physicochem. Eng. Asp. 339, 134-139 (2009) 
31. Vilchis-Nestor, A.R., Sánchez-Mendieta, V., Camacho-López, M.A., Gómez-Espinosa, R.M., Camacho-López, M.A., ArenasAlatorre, J.A.: Solventless synthesis and optical properties of $\mathrm{Au}$ and Ag nanoparticles using Camellia sinensis extract. Mater. Lett. 62(17), 3103-3105 (2008)

32. Mondal, A.K., Mondal, S., Samanta, S., Mallick, S.: Synthesis of ecofriendly silver nanoparticles from plant latex used as an important taxonomic tool for phylogenetic interrelationship. Adv. Biores. 2(1), 122-133 (2011)

33. Vigneshwaran, N., Ashtaputre, N.M., Varadarajan, P.V., Nachane, R.P., Paralikar, K.M., Balasubramanya, R.H.: Biolgical synthesis of silver nanoparticles using the fungus Aspergillus flavus. Mater. Lett. 61, 1413-1418 (2007)

34. Evanoff Jr., D.D., Chumanov, G.: Synthesis and optical properties of silver nanoparticles and arrays. Chem. Phy. Chem. 6, 1221-1231 (2005)

35. Merga, G., Wilson, R., Geoffrey, L., Milosavljevic, B.H., Meisel, D.: Redox catalysis on "naked" silver nanoparticles. J. Phys. Chem. C 111, 12220-12226 (2007)

36. Hu, B., Wang, S.-B., Wang, K., Zhang, M., Yu, S.-H.: Microwave assisted rapid facile "green" synthesis of uniform silver nanoparticles: self-assembly into multilayered films and their optical properties. J. Phys. Chem. 112, 11169-11174 (2008)

37. Zhang, G., Ketia, B., Dolbecq, A., Mialane, P., Secheresse, F., Miserque, F., Nadjo, L.: Green chemistry-type one-step synthesis of silver nanostructures based on $\mathrm{Mo}^{\mathrm{V}}-\mathrm{Mo}^{\mathrm{VI}}$ mixed-valence polyoxometalates. Chem. Mater. 19, 5821-5823 (2007)

38. Luo, L.B., Yu, S.H., Qian, H.S., Zhou, T.: Large-scale fabrication of flexible silver/cross-linked poly (vinyl alcohl) coaxial nanocables by a facile solution approach. J. Am. Chem. Soc. 127, 2822-2823 (2005)

39. Weiping, C., Hofmeister, H., Rainer, T., Wei, C.: Optical properties of $\mathrm{Ag}$ and $\mathrm{Au}$ nanoparticles dispersed within the pores of monolithic mesoporous silica. J. Nanopart. Res. 3, 443-453 (2001)

40. Zhang, H.R., Li, Q.B., Lu, Y.H., Sun, D.H., Ling, X.P., He, N., Zheng, S.Z.: Biosorption and bioreduction of diamine silver complex by Corynebacterium. J. Chem. Technol. Biotechnol. 80, 285-290 (2005)

41. Kumar, A., Abyaneh, M.K., Gosavi, S.W., Kulkarni, S.K., Pasricha, R., Ahmad, A., Khan, M.I.: Nitrate reductase- mediated synthesis of silver nanoparticles from $\mathrm{AgNO}_{3}$. Biotechnol. Lett. 29, 439-445 (2007)

42. Duran, N., Marcato, D.P., Alves, L.O., De Souza, G., Esposito, E.: Mechanical aspect of biosynthesis of silver nanoparticles by several Fusarium oxysporium strains. J. Nanobiotechnol. 3, 8-15 (2005)

43. Sanghi, R., Verma, P.: Biomimetic synthesis and characterisation of protein capped silver nanoparticles. Bioresour. Technol. 100, 501-504 (2009)

44. Phadke, Madhav S. (ed.): Quality engineering using robust design. Prentice Hall, USA (1989)

45. Søren, R., Kadhkhodazadeh, S., Christensen, T., Di Vece, M., Wubs, M., Mortensen, N.A., Stenger, N.: Multipole plasmons and their disappearance in few-nanometre silver nanoparticles. Nat. Commun. 6(8788), 1-9 (2015)

46. Khan, M.A.M., Kumar, S., Ahamed, M., Alrokayan, S.A., Alsalhi, M.S., Alhoshan, M., Aldwayyan, A.S.: Structural and spectroscopic studies of thin film of silver nanoparticles. Appl. Surf. Sci. 257, 10607-10612 (2011)

47. Raza, S., Yan, W., Stenger, N., Wubs, M., Mortensen, N.A.: Blueshift of the surface Plasmon resonance in silver nanoparticles: substrate effects. Opt. Express 21, 27344-27355 (2013)

48. Vigneshwaran, N., Kathe, A.A., Varadarajan, P.V., Nachane, R.P., Balasubramanya, R.H.: Functional finishing of cotton fabrics using silver nanoparticles. J. Nanosci. Nanotechnol. 7, 1893-1897 (2007)

49. Huang, J., Li, Q., Sun, D., Lu, Y., Su, Y., Yang, X., Wang, H., Wang, Y., Shao, W., He, N., Hong, J., Chen, C.: Biosynthesis of silver and gold nanoparticles by novel sun dried Cinnamomum camphora leaf. Nanotechnology 127, 104 (2007)

50. Usha, R., Prabu, E., Palaniswamy, M., Venil, C.K., Rajendran, R.: Synthesis of metal oxide nanoparticles by Streptomyces sp. for development of antimicrobial textiles. Glob. J. Biotechnol. Biochem. 5, 153-160 (2010)

51. El-Rafie, M.H., Mohamed, A.A., Shaheen, Th.I, Hebeish, A.: Antibacterial effect of silver nanoparticles produced by fungal process on cotton fabrics. Carbohydr. Polym. 80, 779-782 (2010)

52. Phadke, M.S. (ed.): Quality engineering using robust design, pp. 101-209, Prentice Hall, USA (1989) 